\title{
PROCESSO DE FORMAÇÃO DO CONCEITO DE COR EM CRIANÇAS DE 8 - 10 ANOS: BUSCANDO INVARIANTES OPERATÓRIOS
}

\author{
GABRIEL DIAS DE CARVALHO JUNIOR ${ }^{*}$ \\ https://orcid.org/0000-0001-7126-1222 \\ ANDRESSA XAVIER ZINATO DE CARVALHO" ** \\ https://orcid.org/0000-0003-3683-2653 \\ RÍSSIA DA SILVA ZACARIAS ${ }^{1 * * *}$ \\ https://orcid.org/0000-0002-9637-4482 \\ MAÍRA DE OLIVEIRA PINTO ${ }^{\prime \cdots * *}$ \\ https://orcid.org/0000-0002-9581-6410
}

RESUMO: Este trabalho foi resultado de uma pesquisa conduzida com 63 crianças de 8 - 10 anos de uma escola pública de Minas Gerais, que está inserida em uma pesquisa longitudinal ainda em curso. Nosso objetivo era identificar invariantes operatórios utilizados pelas crianças em uma situação que envolvia a formação de cores e sombras, por meio de experimentos com projetor. Acompanhamos as soluções propostas pelas crianças e seus registros gráficos. Usamos a Análise de Conteúdo de Bardin e realizamos a identificação dos invariantes operatórios com base na Teoria dos Campos Conceituais. As conclusões indicam que crianças concebem as cores como intensidades distintas de claridade e escuro. Nossa contribuição original é o uso da Teoria dos Campos Conceituais para interpretar o processo conceitualização de cor em crianças.

Palavras-chave: Formação de cores. Conceitualização. Teoria dos campos conceituais.

\section{PROCESO DE FORMACIÓN DEL CONCEPTO DE COLOR EN NIÑOS DE 8 - 10 AÑOS: BUSCANDO INVARIANTES OPERATORIOS}

RESUMEN: Este trabajo resultó de una investigación realizada con 63 niños de 8 a 10 años de edad de una escuela pública de Minas Gerais, que está insertada en una investigación longitudinal aún en desarrollo. Nuestro objetivo era identificar invariantes operatorios utilizados por los niños en una situación que involucraba

*Doutor em Educação pela
Faculdade de Educação da Universidade
Federal de Minas Gerais (UFMG). Professor
do Instituto Federal de Minas Gerais -
campus Ouro Branco. E-mail:
$<$ gabriel.carvalho@ifmg.edu.br $>$
**Especialista em Ensino de
Artes Visuais pela Faculdade
de Belas Artes da Universidade
Federal de Minas Gerais (UFMG).
Pesquisadora do Grupo de
Pesquisas em Campos
Conceituais (GRUPECC). E-mail: $<$
andressazinato@gmail.com $>$
***Graduanda em Pedagogia pelo
Instituto Federal de Minas Gerais -
campus Ouro Branco. Bolsista do
programa Internacionaliza IFMG. E-mail:
$<$ rissiazacarias@hotmail.com $>$
****Graduanda em Pedagogia pelo
Instituto Federal de Minas Gerais -
campus Ouro Branco. Bolsista de
Iniciação Científica do IFMG. E-mail:
$<$ mairadeoliveirapinto.22@gmail.com $>$

I Instituto Federal de Minas Gerais, Ouro Branco, MG - Brasi

II Universidade Federal de Minas Gerais, Faculdade de Belas Artes, Belo Horizonte, MG - Brasil 
la formación de colores y sombras, por medio de experimentos con proyector. Acompañamos las soluciones propuestas por los niños y sus registros gráficos. Usamos el Análisis de Contenido de Bardin y realizamos la identificación de los invariantes operatorios basándonos en la Teoría de los Campos Conceptuales. Las conclusiones indican que niños conciben los colores como intensidades distintas de claridad y oscuridad. Nuestra contribución original es el uso de la Teoría de los Campos Conceptuales para interpretar el proceso de conceptualización de color en niños.

Palabras clave: Formación de colores. Conceptualización. Teoría de los campos conceptuales.

\section{THE COLOR CONCEPT CONSTRUCTION PROCESS IN 8 - 10 YEARS- OLD CHILDREN: LOOKING FOR OPERATIONAL INVARIANTS}

ABSTRACT: This paper was a result of a longitudinal research which is still on course. This research counted with 63 children, students in a public school, from 8 to 10 years old in Minas Gerais state (Brazil). Our goal was to identify which operational invariants were used by the children on a color/ shadow construction situation through the use of a projector. We considered the solutions proposed by the children and also their own graphic notation. We've chosen Bardin's Content Analysis as the methodological approach and we've done, based on Conceptual Fields theory, the identification of the operational invariants. The conclusions point out that the understanding of colors by the children is a result of a differentiation between shades of brightness and dark. Our contribution relies on the new feature brought to Conceptual Fields theory's analytical framework which is the ability to evaluate the colors' conceptualization process in children.

Keywords: Colors construction. Conceptualisation. Conceptual Fields Theory. 


\section{INTRODUÇÃO}

Este trabalho se enquadra em um projeto mais amplo, de natureza longitudinal, que visa descrever e categorizar os invariantes operatórios (VERGNAUD, 2009) utilizados pelos sujeitos em situações envolvendo os conceitos de cor e sombra, desde crianças da educação infantil até adultos. Em uma primeira abordagem, efetuamos a pesquisa em crianças de 5-6 anos (CARVALHO JR; SOUZA, 2017). Estamos na segunda fase desse projeto, agora pesquisando crianças nos anos inicias do Ensino Fundamental.

No presente trabalho, apresentamos os resultados obtidos em pesquisa conduzida junto a 63 crianças entre 8 e 10 anos de uma escola pública municipal de uma cidade no interior de Minas Gerais. As atividades foram realizadas no período regular das aulas das crianças, em três salas distintas de, no máximo, 25 alunos cada uma, perfazendo um total de 200 minutos de intervenção. Para a pesquisa ora relatada, nosso problema foi formulado da seguinte maneira : quais são os invariantes operatórios utilizados por crianças de 8 a 10 anos para abordar e resolver situações envolvendo a formação de cores e de sombras ?

Esse projeto está inserido no campo da Educação em Ciências, mais especificamente na investigação do processo de conceitualização em Ciências. Nesse sentido, pretendemos oferecer mais elementos para a compreensão do processo de formulação conceitual, em geral, e no domínio dos conhecimentos sobre cores e sombras por parte dos aprendizes, em particular. Com o melhor entendimento acerca das formas de pensar e agir dos estudantes nessa área, podem ser planejados, por exemplo, processos de intervenção didática mais adequados ao aprendizado.

Usando como referencial a Teoria dos Campos Conceituais (VERGNAUD, 1990), organizamos uma sequência de atividades práticas demonstrativas e avaliamos as soluções apresentadas pelas crianças para os problemas que iam sendo mostrados ao longo da interação. Nosso interesse estava centrado em interpretar a natureza das falas, dos desenhos e dos textos escritos pelas crianças para solucionar as tarefas. Sendo assim, focamos na tentativa de inferir os invariantes operatórios (VERGNAUD, 2009) utilizados pelas crianças em ação.

O estudo sobre as concepções de crianças sobre cores e sombras se insere em um conjunto mais amplo de pesquisas sobre o conhecimento físico. Nesse sentido, temos os estudos realizados no centro de epistemologia genética de Genebra (PIAGET, 1927; 1967) como a primeira referência em diversas noções sobre a construção do real e da causalidade física.

Por se tratar de um tipo de conhecimento em que as noções cotidianas estão fortemente ligadas na construção dos saberes (VIENNOT, 2002), é importante que as pesquisas foquem aspectos específicos de tal conhecimento.

Do ponto de vista dos trabalhos ligados estritamente à formação de cores e sombras, a investigação conduzida por Guesne (1985) indicou haver uma tendência a considerar que a cor é uma característica intrínseca do objeto observado. A pesquisadora utiliza em sua investigação objetos coloridos iluminados por luz branca. Nessa perspectiva, a conclusão geral é a de que as crianças pensam que a luz simplesmente ilumina os objetos, mas não possui influência sobre a formação 
da sua cor. Essa conclusão é encontrada em trabalhos correlatos (ANDERSSON ; KARQVIST, 1983 ; FEHER ; RICE, 1985).

Utilizando uma metodologia diferenciada, que acrescenta luzes coloridas para a visualização de objetos e realizada em um espaço não escolar, Feher e Meyer (1992) pesquisaram crianças de 8 a 13 anos que visitavam um museu de ciências onde havia experimentos realizados com luzes artificiais de iluminação pública e salas fechadas iluminadas, cada uma delas, com uma das cores primárias (vermelho, verde e azul). Nessa pesquisa, cada criança, de posse de objetos coloridos, transita entre os ambientes com diferentes iluminações, tendo que realizar previsões sobre a cor que enxergaria tais objetos e como seriam as sombras projetadas. Em seguida, as crianças foram entrevistadas individualmente e tiveram que comparar suas previsões com os resultados observados. Uma das conclusões mais interessantes é a de que a maioria das crianças entrevistadas considera que a cor é uma espécie de grau de escuridão, ideia que remonta às concepções de Aristóteles e, de certa forma, reeditadas em Goethe (FEHER ; MEYER, 1992, p. 505).

Com o interesse restrito às formas utilizadas por crianças de 8 a 11 anos para resolver situações envolvendo a formação de sombras, Gonçalves e Carvalho (1995) identificam, em consonância com as pesquisas piagetianas, algumas fases do desenvolvimento desta noção. Para as autoras, as crianças passam de uma concepção da sombra como uma substância, usam a ideia de sombra como um reflexo do objeto para, enfim, adquirir uma concepção ligada à ausência de luz. A metodologia desta pesquisa indica o interesse das autoras em investigar a construção de relações causais quando da realização de tarefas de projeção de sombras.

O trabalho de Mota e Santos (2018) usa um modelo desenvolvido por eles, chamado ATC (Addition Table of Colours) para ensinar a adição de cores para estudantes de 12 a 13 anos. Usando o Modelo de Mudança Conceitual, os autores construíram uma sequência didática, aplicada a 250 alunos e seguiu o ensino tradicional com outros 204 alunos. Os autores concluem que o modelo ATC é mais eficaz para a compreensão crítica do fenômeno da cor.

Os autores supracitados apresentam uma interessante sumarização das principais ideias que as crianças apresentam sobre a formação de cores. O quadro a seguir foi adaptado do trabalho original dos autores (MOTA; SANTOS, 2018, p. 95) :

Quadro 1. Concepções de crianças sobre a formação de cores

A cor é uma propriedade do objeto e é independente da luz que o ilumina.

A cor é uma propriedade do objeto que não se altera quando a luz branca incide nele mas que pode mudar se ele receber luz colorida.

Cores escuras cobrem cores claras.

A mistura de luzes segue a mesma regra da mistura de tintas.

A luz branca não tem cor e é clara, o que permite a visualização da cor real dos objetos.

A cor de uma sombra é sempre a cor da fonte de luz usada. 
Castro e Rodriguez (2014) realizaram entrevistas com mais de uma centena de crianças entre 8 e 9 anos para constatar que elas utilizam diferentes representações sobre a luz e que raramente reconhecem a luz como uma entidade independente das fontes e dos efeitos produzidos.

Em trabalho recente, Martínez-Borreguero et al. (2013) concluíram que as concepções alternativas sobre cores parecem ter uma consistência interna. Pesquisando estudantes de graduação, os autores encontraram quatro «mini teorias » que funcionam como a base da construção de explicações em situações simples. Essas, no entanto, podem funcionar de forma solidária, serem modificadas ou transformadas em situações complexas que exigem a articulação de conceitos, como no caso da mistura de cores.

Nota-se, portanto, haver uma preocupação já antiga na investigação sobre o processo de conceitualização no campo da formação de sombra e de cores. As pesquisas já conduzidas são diversas em relação às metodologias, aos referenciais teóricos e aos sujeitos.

Inserido nesse contexto dessas pesquisas, o presente trabalho acrescenta à discussão já existente em três pontos principais : (1) propõe uma análise das enunciações das crianças a partir de um enfoque psicológico a partir da utilização da Teoria dos Campos Conceituais ; (2) apresenta uma metodologia de pesquisa que privilegia a participação do coletivo dos estudantes e de suas trocas verbais, em um ambiente em que são propostas situações para que eles resolvam ; (3) faz parte de um estudo longitudinal, realizado com sujeitos de diversas faixas etárias, o que permitirá uma análise genética das noções de cores e sombras.

\section{REFERENCIAL TEÓRICO}

\section{A TEORIA DOS CAMPOS CONCEITUAIS}

A teoria dos campos conceituais (TCC) foi proposta inicialmente pelo psicólogo francês Gérard Vergnaud para explicar a complexidade do processo de conceitualização e para fazer a diferença entre as formas predicativa e operatória do conhecimento (VERGNAUD, 1990). De inspiração piagetiana, a TCC dialoga com a psicologia sociocultural, sobretudo no que se refere às concepções de conceito como uma ferramenta cultural utilizada, sempre, em situação.

Em Vergnaud (2003), não faz sentido se discutir e estudar um conceito isoladamente e em um curto espaço de tempo. Ao contrário, os conceitos estão estritamente ligados entre si em redes - os campos conceituais - e são dominados pelos sujeitos em grandes espaços de tempo (CARVALHO JR., 2013).

Para lidar com o processo desenvolvido em cada sujeito, Vergnaud (2002) lança mão do conceito de esquema, entendido como a organização invariante da atividade para uma dada classe de situações. Os esquemas de cada sujeito evoluem desde a mais tenra idade a partir das inúmeras situações enfrentadas (CARVALHO JR. ; PARRAT-DAYAN, 2013).

Vergnaud reconhece quatro dimensões que compõem um esquema : (1) as regras de ação e controle, que guiam a tomada de dados e o seu processamento e indicam as necessidades de repetição da ação; (2) as metas e submetas, 
associadas ao reconhecimento do que deve ser obtido como resultado da ação ; (3) as possibilidades de inferência, que tornam os esquemas diferentes de meros algoritmos ; (4) os invariantes operatórios (VERGNAUD, 2005).

Por outro lado, o autor apresenta uma formulação própria para os conceitos, ligada a uma dimensão cultural. Nesse sentido, há três dimensões indissociáveis para um conceito : (1) as situações, onde repousa a operacionalidade dos conceitos, aqui entendidas como tarefas reconhecidas pelo sujeito como algo que deva ser enfrentado e resolvido ; (2) as representações, formas verbais, escritas, pictóricas, etc., de se referir a um conceito ; (3) os invariantes operatórios (VERGNAUD, 2003).

De acordo com a definição de esquema, os invariantes operatórios representam a parte que está associada aos conhecimentos utilizados para dar conta da situação. Do ponto de vista dos conceitos que podem ser usados para que o sujeito resolva as situações, os invariantes operatórios representam os conhecimentos disponíveis culturalmente. Em razão disso, Vergnaud (1990) também os chama de conhecimentos-em-ação.

Portanto, os invariantes operatórios representam um papel importante em toda ação dos sujeitos. Por meio deles, um sujeito reconhece alguns conceitos como pertinentes para a construção de uma solução satisfatória. Esses conceitos tidos como pertinentes na ação são chamados, na TCC, de conceitos-em-ação. Em situação, dado sujeito formula proposições, construindo relações entre os conceitos-em-ação. Essas proposições são tidas como verdadeiras pelo sujeito e, de acordo com ele, possibilitarão a resolução da situação. Esses são os teoremasem-ação. (CARVALHO JR., 2013).

No trabalho de Mota e Santos (2018), por exemplo, os autores identificam a concepção de que a «mistura de luzes segue a mesma regra da mistura de tintas ». Essa concepção pode, à luz da Teoria dos Campos Conceituais, ser desdobrada em duas instâncias indissolúveis complementares : os conceitos-em-ação e os teoremas-em-ação. ${ }^{1}$

Parece-nos que os conceitos de cor, composição, luz e pigmento são utilizados, implicitamente, como as bases para a construção das explicações sobre as misturas de luzes e tintas. Esses são os conceitos-em-ação. Com eles, é construída uma proposição sobre a situação que irá guiar as formas de agir e as previsões sobre os resultados que poderão ser alcançados em situações práticas. Tal proposição, enunciada pelos autores como sendo uma concepção, é o teorema-em-ação.

Nesse sentido, chamamos, genericamente, de invariantes operatórios os conceitos-em-ação e os teoremas-em-ação.

Esses invariantes operatórios permanecem implícitos durante a ação e evoluem temporalmente na medida em que dado sujeito enfrenta situações de uma mesma classe cada vez mais complexas. Eles não são conceitos e teoremas científicos, visto não serem demonstráveis nem explicitáveis. No entanto, podem evoluir ao longo de certo intervalo de tempo para se aproximarem das formulações científicas. Por isso, defendemos a ideia de que o processo de conceitualização em ciências é um sistema complexo que ocorre no sentido de aumentar quantitativa e qualitativamente os invariantes operatórios dos sujeitos tendo como referência conceitos e relações tais como compreendidos pela ciência. 
Nesse sentido, os invariantes operatórios, por fazerem parte dos dois domínios (esquemas e conceitos), podem ser compreendidos como o elo entre eles. Esta é a razão pela qual defendemos que as pesquisas em conceitualização, sob a ótica da TCC, necessitam ter como porta de entrada a investigação dos invariantes operatórios utilizados pelos sujeitos durante a realização de tarefas que os desafiem.

\section{COMPOSIC̣ÃO DE CORES}

A apropriação que fizemos sobre o complexo processo de formação de cores e a sua percepção foi ligada às sínteses aditiva e subtrativa (PARRAMÓN, 1993). Para tanto, torna-se importante diferenciar as cores-luz e as cores-pigmentos.

As cores-luz estão ligadas às ondas eletromagnéticas de diversas frequências que podem ser adicionadas umas às outras, criando diversas sensações visuais para os sujeitos. O famoso experimento conduzido por Isaac Newton com um prisma triangular, fazendo com que a luz solar fosse dispersada em suas componentes exemplifica essas cores-luz.

Por outro lado, o disco de Newton é uma maneira de se fazer uma mistura de luzes de diversas cores e, com isso, gerar o branco. Um disco é dividido em setores (seis, sete ou mais setores). Cada setor é pintado com uma cor diferente, de tal forma a cobrir todo o espectro de cores (do vermelho ao violeta). Quando esse disco é posto em rotação rápida, nosso olho percebe, de cada ponto, diversas luzes emergindo. Essa mistura de luzes nos dá a sensação de ver o branco. Esse efeito é, portanto, do tipo aditivo, onde as luzes se adicionam. O físico inglês Isaac Newton mostrou, em um célebre experimento realizado com um prisma triangular atravessado pela luz solar, que esta é formada pela mistura de luzes de todas as cores. No citado experimento, a luz solar, passando pelo prisma, se decompõe e é projetada em uma tela, onde aparecem todas as cores que vemos no arco-íris. Nesse sentido, os fenômenos da dispersão no prisma e da composição no disco de Newton são complementares e podem ser utilizados para ilustrar o mesmo conceito.

No caso de cores-luz, temos três fontes chamadas de primárias : vermelho, verde e azul. A partir da síntese dessas três, é possível produzir qualquer outra cor. As sínteses aditivas, realizadas duas a duas, são : vermelho + verde $=$ amarelo ; vermelho + azul $=$ magenta ; verde + azul $=$ ciano.

Quando utilizamos cores-pigmento, a situação se torna diferente. O pigmento é capaz de absorver certas cores e refletir outras. Os pigmentos considerados como primários são : ciano, amarelo e magenta. O seu efeito é o de supressão de cores (síntese substrativa). Quando diversos pigmentos são misturados (por exemplo, diversas tintas de diferentes cores são misturadas), cada pigmento absorve certas luzes a partir da luz original incidente. O efeito da mistura de diversos pigmentos é, portanto, o preto.

Nesse sentido, ao se fazer o estudo das cores-pigmento, pelo fato de operarmos com a lógica da aborção de parte da luz incidente, a tendência é que haja uma redução na luminosidade se forem comparadas essas situações com as da lógica aditiva. Dessa forma, os estudos de cores-luz e cores-pigmento colocam em evidência dois fenômenos óticos complementares. 


\section{METODOLOGIA DA PESQUISA}

\section{SUJEITOS E CONTEXTOS}

As atividades de pesquisa ocorreram no segundo semestre de 2018, em uma escola municipal de uma cidade do interior de Minas Gerais. Essa escola atende crianças e adolescentes do meio urbano e conta com grande prestígio local.

O público pesquisado foi composto por crianças de idade média de 9 anos, cursando o terceiro ano do ensino fundamental. A escola conta com 4 turmas de terceiro ano, sendo cada uma delas com 25 alunos. Realizamos a intervenção de pesquisa em três dessas turmas, escolhidas aleatoriamente, em função da disponibilidade de tempo da escola.

Os professores das turmas são exclusivos da escola e ministram aulas de língua portuguesa, matemática, ciências da natureza e humanas. Há um professor especializado de Artes para as turmas.

O acesso à escola é feito mediante seleção prévia, já que há mais candidatos que vagas disponíveis. Tal seleção leva em conta aspectos ligados ao local de moradia e à condição socioeconômica dos estudantes. Os estudantes que moram mais perto da escola e que possuem condição socioeconômica mais desfavorável possuem preferência no preenchimento das vagas. Esses são selecionados a partir de um cadastro prévio de interesse que é realizado segundo calendário anual disponibilizado pela prefeitura.

Em geral, as crianças nos acolheram com muito entusiasmo e disposição para o trabalho.

Após negociação com a direção e coordenação pedagógica, onde foram apresentados os planos de intervenção e os termos de esclarecimento e livre consentimento, ficou acertado que as atividades durariam cerca de 60 minutos em cada classe.

Participaram das atividades em sala de aula, como pesquisadores, quatro professores do nosso grupo de pesquisas e duas estudantes do curso de Pedagogia. O pesquisador líder do grupo conduziu as demonstrações e os questionamentos às crianças.

\section{SISTEMÁTICA DE CONSTRUCְÃO DOS DADOS}

As atividades foram registradas somente em áudio, porque a direção da escola, seguindo determinação da secretaria municipal de educação, não permitiu o registro em vídeo. Nesse sentido, cada pesquisador se posicionou em diferentes locais da sala de aula e efetuou o registro de áudio, além de proceder às anotações em seus cadernos de campo.

As crianças foram identificadas por números (de 1 a 25 em cada turma), de acordo com o local em que estavam assentadas e receberam folhas de papel A4 com o respectivo número impresso.

Além dos episódios de interação verbal entre o grupo de pesquisa e as crianças, foi solicitado um registro final sobre as atividades. Nesse sentido, além da folha em branco numerada, cada criança recebeu três lápis de cor (um azul, um 
vermelho e outro verde), que era somente o material que elas poderiam usar para registrar as atividades que foram propostas.

Em cada seção de pesquisa, utilizamos os mesmos materiais para efetuar as demonstrações empíricas e recolher os dados.

A. Um disco de Newton com seis setores circulares, cada um deles colorido com as seguintes cores : vermelha, laranja, amarela, verde, azul e violeta.

B. Um projetor LED com 18 fontes luminosas, sendo 6 vermelhas, 6 azuis e seis verdes. Esse projetor permite que sejam ligadas somente uma das cores, duas delas ou todas.

C. Folhas brancas numeradas para que as crianças pudessem registrar suas produções.

D. Três lápis de cor para cada criança, sendo um vermelho, um azul e o outro verde.

E. Objetos opacos para produção de sombra.

Apresentamos, a seguir, a sequência das atividades aplicadas nas três turmas, indicando os objetivos de cada uma delas.

Inicialmente, conduzimos uma conversa com a turma no sentido de apresentar o objetivo das atividades e que não se tratava de algo que « valesse ponto ». Nesse sentido, todas as crianças podiam se sentir à vontade para expor suas próprias ideias, sem se preocupar com o fato de estarem certas ou erradas. Em seguida, começamos a falar sobre as cores, perguntando às crianças qual a cor preferida, se elas já haviam visto arco-íris, etc. O objetivo desse momento inicial era de criar um ambiente propício para apresentar os experimentos sobre a formação de cores e sombras. Em seguida, conduzimos à realização das atividades seguintes, todas elas realizadas em uma sala de aula escurecida.

\section{A. Atividade 1 : Disco de Newton}

Usando um disco cartolina furado em seu centro por um lápis, pintado com seis cores (vermelho, laranja, amarelo, verde, azul e violeta), fizemos o mesmo girar rapidamente. Como resultado, as luzes emergentes de cada setor do disco se misturam, dando a sensação de estar vendo o branco. Realizamos o experimento da fusão das cores e demandamos às crianças explicarem a razão da mudança da sensação de cores.

Em seguida, usando o projetor, iluminamos o disco de Newton somente com a luz vermelha e demandamos às crianças a explicação dessa mudança de visualização.

Queríamos, com isso, iniciar a discussão acerca da diferença entre o que vemos sob luz branca e o que pode mudar quando uma luz monocromática incide sobre os objetos. Com isso, criamos uma situação em que há uma diferença entre a forma como um mesmo objeto é visto quando iluminado por fontes luminosas distintas. 


\section{B. Atividade 2 : Projecãa de luz monocromática e de sombra}

A segunda atividade, usando o projetor emitindo somente a luz vermelha, consistiu em lançar luz vermelha no teto que é branco. O objetivo inicial é dar continuidade à discussão sobre o uso de uma luz monocromática para iluminar os objetos. Em seguida, queríamos introduzir a ideia de que um objeto opaco pode impedir a passagem da luz e, com isso, gerar uma sombra escura. A explicação de que a sombra escura aparece quando um corpo opaco impede a passagem da luz é de fácil compreensão e foi indicada pelas crianças. Essa etapa da atividade não foi colocada com um interesse direto de pesquisa.

O objetivo final era o de iniciar a construção de uma situação inusitada quando da projeção de sombras coloridas.

\section{Atividade 3 : Mistura de cores duas a duas e projeção de sombras coloridas}

A terceira etapa consistiu em usar o projetor com dois tipos de luzes acionados : vermelha e verde, para projetar o amarelo ; vermelha e azul, para projetar o magenta; verde e azul, para projetar o ciano.

Para cada caso, as luzes utilizadas eram mostradas às crianças e, em sequência, o projetor era virado para o teto.

Em seguida, um objeto opaco (a mão do pesquisador ou uma folha branca) era colocado à frente do projetor. Nesse caso, apareciam uma sombra escura no centro e duas sombras coloridas, cada uma com uma das cores das fontes. Por exemplo, quando as luzes vermelha e azul eram utilizadas, apareciam uma sombra escura no centro e duas outras, uma vermelha e a outra, azul, conforme mostra a figura a seguir.

Figura 01. Projeção de sombras coloridas usando as fontes vermelha e azul

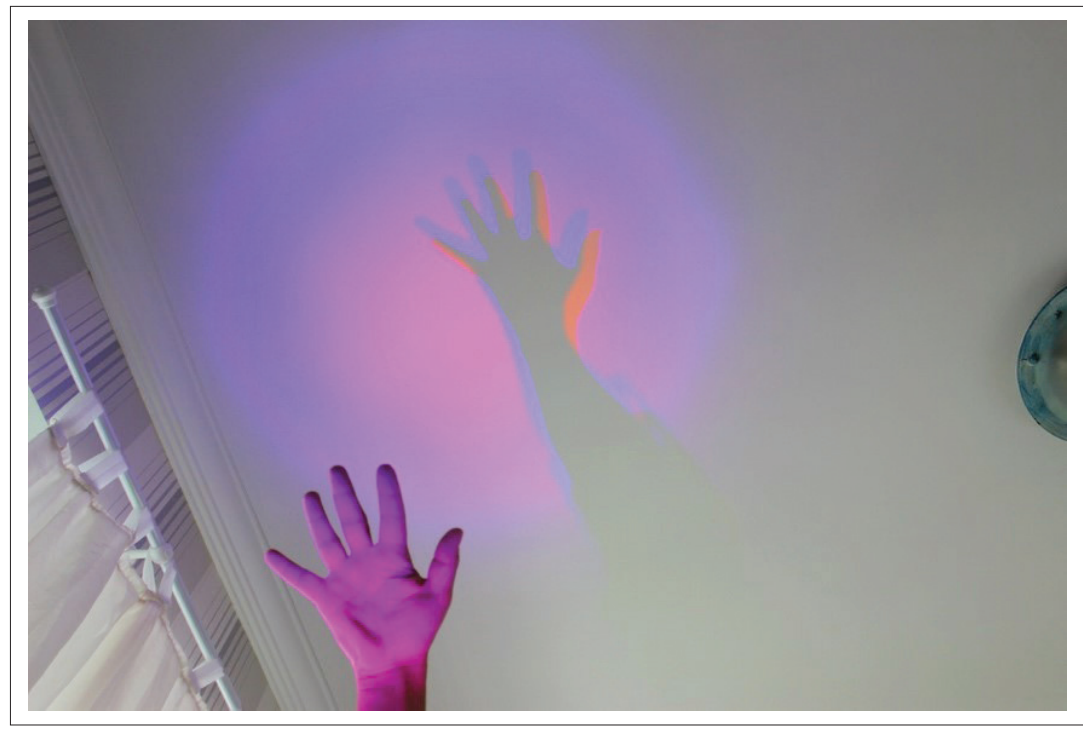

Fonte : Autor 
Antes da formação das sombras, no entanto, as crianças eram questionadas sobre o que iria acontecer se a mão fosse colocada à frente do projetor. A resposta era a de que apareceria uma sombra escura, como aquela que fora vista quando da utilização da luz monocromática.

Queríamos apresentar uma situação inusitada, que fosse contrária ao que era esperado pelas crianças, em uma típica situação que gera desequilíbrio cognitivo. As explicações apresentadas pelas crianças giravam em torno de uma lógica linear, sem a apresentação de uma relação de causa e consequência. Em geral, as crianças disseram que as sombras eram coloridas porque a fonte era colorida, associando as cores das sombras às luzes utilizadas no projetor.

\section{Atividade 4 : Uso das três cores juntas e projeção de sombras coloridas}

A última etapa consistia em usar as três cores juntas, formando o branco.

As crianças foram, então, questionadas acerca do que iria acontecer se a mão fosse colocada à frente do projetor. As crianças indicaram, em geral, que iriam aparecer sombras coloridas, com as cores vermelha, verde e azul, em clara extensão do experimento anteriormente realizado.

Quando o experimento é, de fato, feito, aparecem sombras com as cores citadas pelas crianças e outras três : amarela, ciano e magenta.

Essa foi mais uma situação em que as crianças se sentiram desequilibradas ao tomarem consciência de que os que estavam vendo excedia ao que tinha sido previsto.

\section{E. Atividade 5 : Registro e explicação}

Após essas atividades, as crianças receberam os três lápis de cor (um vermelho, um azul e outro verde) e uma folha numerada para tentarem reproduzir o último experimento de mistura das cores. Foi solicitado que eles desenhassem, usando os lápis recebidos, a mistura de cores que fizemos com o projetor. Além disso, também foi dito que eles poderiam escrever o que achassem pertinente e efetuar outros desenhos auxiliares. Algumas crianças realizaram a mistura de cores duas a duas, como havia sido feito na atividade 3. Outras se limitaram a seguir a orientação de tentar produzir o branco a partir dos três lápis que receberam.

O objetivo aqui era o de apresentar uma contradição entre o que havia sido feito pelo pesquisador ao projetar as três luzes coloridas e a produção das crianças, usando os três lápis de cor e verificar (1) se as crianças conseguiriam tomar consciência de tal contradição e (2) de que maneira elas iriam lidar com essa contradição e proporiam a sua resolução. Acreditávamos que, assim procedendo, conseguiríamos obter material empírico suficiente para inferir os invariantes operatórios utilizados pelas crianças.

Pouco a pouco, as crianças foram se dando conta de que colorindo com os três lápis, o resultado era o oposto do havia sido feito com o projetor, fato que gerou inquietude e questionamento por parte delas. Por iniciativa própria, diversas crianças tentaram alternativas, alterando a ordem dos lápis utilizados, procurando colorir com menos pressão nos lápis ou propondo usar outros materiais (canetinhas, por exemplo). 
Foi conduzida uma discussão com as turmas no sentido de verificar quais seriam as explicações para os resultados obtidos pelas crianças.

Por fim, após as crianças terem testado suas hipóteses e realizado os desenhos, foi solicitado que cada criança redigisse uma explicação para a diferença entre o que foi projetado e o que foi obtido pelo desenho de cada uma. Esses registros foram recolhidos, digitalizados e interpretados pelo grupo de pesquisa.

\section{SISTEMÁTICA DE INTERPRETAC̣̃̃O DOS DADOS}

O sistema construído para interpretação dos dados de pesquisa começou com a realização de três reuniões do grupo de pesquisa onde cada membro pode explicitar suas impressões sobre as atividades realizadas e destacar os pontos que julgou mais relevante nas produções das crianças.

Após esse momento, foi realizada uma primeira investida de interpretação dos dados, construindo categorias de análise, a partir da análise de conteúdo (BARDIN, 1977). Nosso interesse em utilizar tal modelo de interpretação dos dados se deve à nossa necessidade de inferir invariantes operatórios, construtos que, segundo Vergnaud (2002), permanecem implícitos na maior parte da ação dos sujeitos. Dessa forma, a análise de conteúdo de Bardin nos auxiliou na identificação dos significados que estavam subjacentes na realização das tarefas propostas.

Nossa pré-análise dos dados contou com a leitura das produções escritas de todas as crianças e a escuta dos áudios das intervenções. Em seguida, fizemos anotações sobre os modelos de resposta mais recorrentes para tentar alocar as respostas das crianças nessas primeiras categorias. Esse primeiro esforço de categorização foi apresentado ao grupo de pesquisa, onde foi possível o cruzamento das interpretações entre os pesquisadores envolvidos nesse projeto.

Separamos, então, os turnos de fala e as produções escritas mais representativas de cada categoria e estabelecemos quais seriam as diferenças aceitáveis entre as respostas para a inclusão nas categorias.

Após esse procedimento, voltamos aos dados já organizados para verificarmos a consistência entre nossas análises iniciais e as categorias consensuadas entre os pesquisadores. Repetimos esse procedimento de interpretação, avaliação das categorias e verificação de consistência ainda por 2 vezes até chegarmos nas categorias que serão apresentadas mais à frente.

Nesse processo, inferimos algumas variáveis que são, enfim, os indícios dos invariantes operatórios utilizados pelas crianças. As variáveis inferidas foram (1) a cor como luminosidade, (2) a composição da cor dependente da ordem em que as cores foram misturadas e (3) a cor como propriedade intrínseca ao objeto.

Em seguida, com a organização das categorias, focamos nossa atenção nas formas mais frequentes de interpretação do experimento proposto na atividade 4, para identificar os invariantes operatórios e organizá-los de forma a construir alguns possíveis modos de agir das crianças. Por fim, selecionamos textos escritos, desenhos e falas que fossem exemplares desses invariantes operatórios identificados para apresentar nesse artigo. 


\section{EPISÓDIOS E INTERPRETAC̣ÕES}

Os episódios que serão trabalhados são aqueles ligados às atividades 4 e 5, visto serem o foco central de nossa investigação.

No sentido de garantir o anonimato, identificaremos as crianças por um código de seis algarismos, ligados por hífens. Os dois primeiros referem-se ao número da folha que identifica a criança; os dois seguintes são o dia em que a pesquisa foi realizada ; os dois últimos são o mês de realização da pesquisa.

Como já citado, as crianças e os professores foram muito receptivos e interagiram de forma muito intensa com os pesquisadores, procurando apresentar suas explicações e suas inquietudes. Em diversos momentos ao longo das atividades 2 a 4, percebemos explicações tautológicas, muito comum nessa faixa etária, onde a lógica dos atributos dos objetos é decisiva para a construção dos enunciados (PIAGET ; GARCIA, 1987).

Assim, na atividade envolvendo o Disco de Newton, quando a luz vermelha foi lançada sobre o disco e o pesquisador perguntou a razão da mudança, em todas as turmas, as crianças indicaram que foi por causa do projetor. Ao insistir na pergunta, indagando o que o projetor fez para alterar as cores do disco, as crianças disseram que ele usou a luz vermelha.

Então, o pesquisador reforça a pergunta, demandando qual a razão para que, quando o projetor é ligado, as cores percebidas serem diferentes. As respostas das crianças em todas as turmas pode ser resumida pelo enunciado por uma criança e já indica um avanço em relação aos anteriores.

(12-31-10) : « quando põe luz vermelha, o vermelho é forte ... o amarelo é mais fraco ...

Esse turno de fala indica a ideia de que o projetor é « mais forte » que o disco e, de certa forma, «impõe » a sua cor àquela que é própria do setor amarelo do disco.

A partir desse tipo de enunciado e de resultados de outras pesquisas neste campo (GUESNE, 1985 ; FEHER ; MEYER, 1992 ; VIENNOT, 2002), é possível estabelecer a ideia de que as crianças acreditam que a cor percebida do disco de Newton é uma propriedade dele e, não o resultado da interação entre o objeto e a luz que o ilumina. No entanto, essa propriedade pode ser alterada se outro objeto « mais forte » produzir tal mudança.

Como veremos a seguir, essa ideia de que uma fonte mais forte pode alterar as propriedades de outro aparecerá com grande intensidade na resolução da contradição que apresentamos às crianças.

Para a apresentação dos episódios ligados à diferença entre o projetado e o desenhado, optamos por indicar algumas das produções escritas mais representativas, assim como alguns desenhos que mais bem ilustram os invariantes operatórios identificados.

Dentre as 63 crianças cujas produções puderam ser avaliadas, percebemos uma grande categoria que indica que as diferenças entre o observado pela projeção das luzes e o desenho são devidas às diferenças entre os objetos utilizados (diferença entre lápis e projetor). Nessa categoria, encontramos 56 crianças. As outras 7 crianças apresentam explicações ligadas às características da folha (ser muito clara), 
à decomposição das cores (sem entrar em detalhes sobre o que isso significa), à madeira (sem explicar o que isso significa) ou não apresentaram respostas.

Dentro da categoria « diferença entre lápis e projetor», porém, as respostas não foram uniformes.

A maior subcategoria, com 32 crianças, indica explicitamente que o projetor é um objeto « mais claro » que o lápis e, por isso, consegue produzir o branco. Já o lápis, por ser mais escuro, só consegue produzir tonalidades escuras.

(10-01-11) : «a luz é mais forte que o lápis »

(01-01-11) : «porque a luz é forte e a cor do lápis é fraco»

(15-01-11) : «porque a luz é mais forte que o lápis »

(09-29-10) : «porque e uma luz que dá claridade e no lapis não dá »

(20-31-10) : «porque é a claridade, mas se colorir fraco eu acho que dá »

(05-29-10) : «porque o lapis é mais escuro »

Figura 02. Produção escrita do estudante 20-31-10

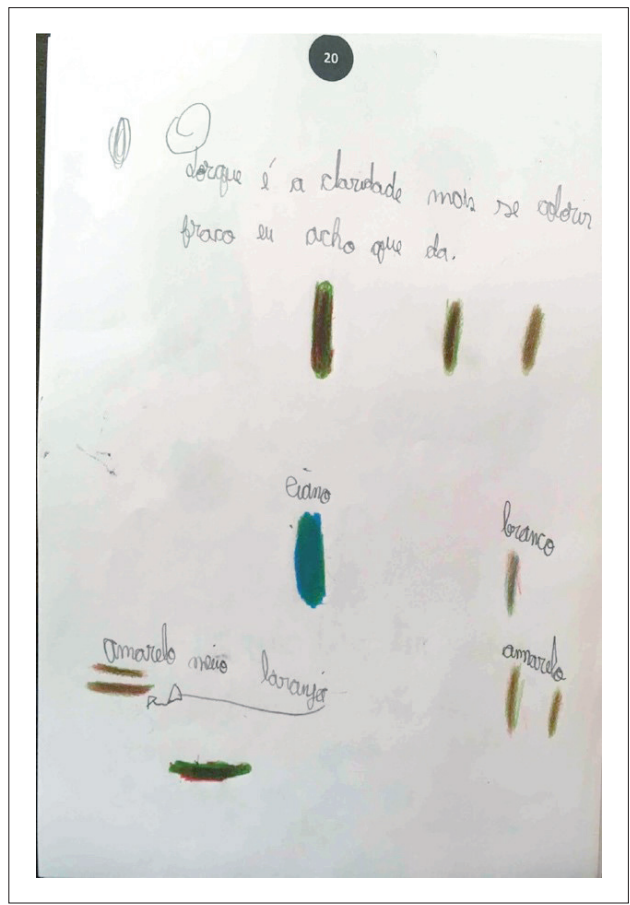

Fonte: Gabriel Dias de Carvalho Júnior 
Figura 03. Produção escrita do estudante 05-29-10
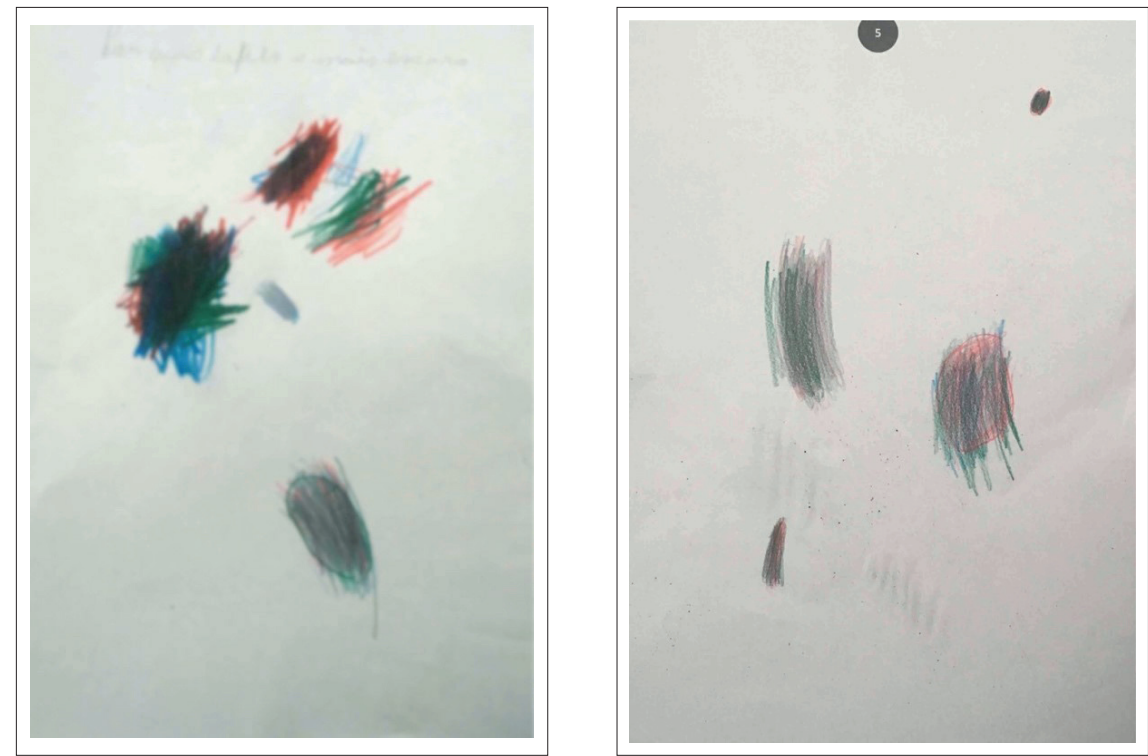

Fonte: Gabriel Dias de Carvalho Júnior

Em seguida, há um grupo que, simplesmente, afirma haver diferenças entre o lápis e o projetor, sem identificar a claridade como fator que os diferencia. Nesta subcategoria, há 19 crianças.

(04-01-11) : « nas cores de lápis não dá. Tem alguma coisa diferente aí no seu $<<$ projetor $>>$

(06-29-10) : «porque a lus forma sozinha e nos não conseguimos »

(03-29-10) : « a luz tem um tom diferente»

As duas outras subcategorias possuem poucos representantes. Em uma delas, 3 crianças afirmam que o projetor é mais escuro que o lápis. Na outra, 2 crianças afirmam que o projetor consegue juntar as cores e o lápis, não.

A despeito dessas subcategorias, há algo curioso que une ainda mais as respostas das crianças de todas as categorias e que está ligada à função dos invariantes operatórios no processo de resolução de problemas (CARVALHO JR., 2013). Frente a uma situação, determinado sujeito atribui como pertinente um ou vários conceitos (os conceitos-em-ação) para a resolução satisfatória, realizando, com tais conceitos, proposições tidas como verdadeiras (os teoremas-em-ação). Essas atribuições são a base do exercício de um esquema. Em um segundo momento, o sujeito tenta operacionalizar o que havia sido estabelecido sobre a ação. Entra em jogo, outra característica dos esquemas que é o mecanismo de controle. Se o resultado da ação do esquema for satisfatória, no sentido de produzir 
um resultado esperado, dá-se por resolvido o problema por parte do sujeito. Caso contrário, outros invariantes operatórios devem ser levados em conta.

Pois bem, quando os estudantes foram solicitados a reproduzir em desenho a projeção das três cores utilizando, somente, três lápis de cor, utilizaram uma ordem aleatória para colorir a folha com a expectativa que a mistura das três cores resultaria em branco. Nesse momento, não havia um problema a ser resolvido, visto que as três cores dos lápis eram, exatamente, as três vistas no projetor. Em outras palavras, tratava-se, apenas e tão somente, de uma reprodução simples.

$O$ problema apareceu quando o colorido realizado pelas crianças não resultou na produção do branco. A partir daí, dois conceitos-em-ação distintos foram majoritariamente utilizados pelas crianças.

O primeiro, utilizado por 35 crianças, foi a ordem em que se colore, com o consequente teorema-em-ação « há uma ordem correta de colorir que produz. 0 branco ». Essa forma de agir fez com que as crianças, independente da explicação final produzida, tentassem colorir usando ordens diferentes (mas, de forma não sistemática) na expectativa de que alguma delas conduzisse ao branco. Esta concepção pode estar ligada à ideia de que cada cor pode suprimir determinada quantidade da luz e que há uma ordem correta em que tal supressão seja minorada e conduza ao branco. Em outras palavras, configura-se em uma organização mais complexa que pode levar à construção do conceito de absorção luminosa, conceito científico pertinente para a explicação da situação proposta. Essa ideia, muito mais vaga e lacunar, também fora encontrada em outro trabalho sobre o mesmo assunto que utilizou, no entanto, crianças mais novas como sujeitos de pesquisa (CARVALHO JR; SOUZA, 2017).

No entanto, o insucesso em se conseguir reproduzir o que havia sido visto motivou as crianças a procurarem outros conceitos julgados como pertinentes. Dentre as 35 crianças, 16, além de outras 7 que não haviam explicitado a ordem como determinante, identificaram que a pressão com que se coloria poderia ser um conceito pertinente para, então, explicar a diferença. Os teoremas-em-ação « quanto menor a pressão exercida para colorir, mais claro fica o desenho » e « quanto mais claro o desenho, mais próximo de branco vai ficar » são admitidos como verdadeiros neste momento. Essas crianças fizeram, então, outros desenhos, colorindo a folha com pouca pressão, na expectativa de obter o branco. Nesse caso, o insucesso em realizar a tarefa causou frustração às crianças. 
Figura 04. Produção escrita do estudante 14-29-10

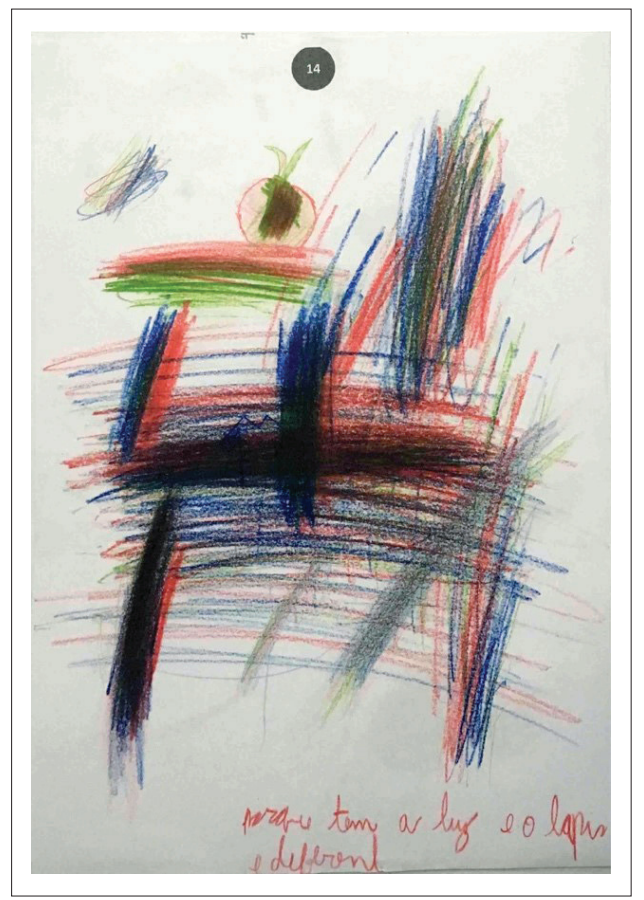

Fonte: Gabriel Dias de Carvalho Júnior

$\mathrm{Na}$ figura anterior, os números indicam etapas da produção dos desenhos. No início, a criança coloriu fortemente em duas ordens distintas, sendo que em (1) a última cor foi a azul e em (2) foi a verde. Na parte (3), a criança já tentou colorir com menos pressão, e foi assim diminuindo nas partes (4) e (5).

Algumas dessas crianças tentaram outras possibilidades, ainda ligadas ao conceito em ação de claridade. Algumas crianças explicitaram que se fosse colorido com canetinhas, ou se fossem utilizados outros lápis de cor mais claros ou elementos mais "molhados ", o resultado seria o branco.

(10-01-11) : « . . e se a gente tentar de canetinha ? <<após termos permitido que ela usasse as canetinhas, a criança faz o colorido $>>$ Não deu, deu preto ».

Para diversas crianças, a explicação da claridade encontrou um referente empírico associado ao projetor, que foi o único elemento que, de fato, gerou o branco. O curioso é que mesmo não tendo conseguido produzir o branco com lápis ou canetinhas, a explicação ligada à claridade parece ter sido satisfatória para as crianças, pois elas continuaram a dizer que o projetor era mais claro que os lápis. 


\section{CONCLUSÃO}

Nosso objetivo central era o de identificar invariantes operatórios utilizados pelas crianças para dar conta de uma situação conflitante ligada à formação de cores e sombras. Esses resultados nos servirão na construção de uma análise genética nessa área visto que ainda está em curso o estudo longitudinal sobre o tema.

Percebemos uma forte correlação entre nossos resultados e outros obtidos em pesquisas sobre o mesmo tema, mesmo usando metodologias e amostras diferentes. Em geral, ressaltamos que as crianças atribuem à diferença entre a soma das luzes projetadas e o resultado dos seus desenhos a alguma propriedade do projetor que não se encontra nos lápis, notadamente a claridade. Essa concepção remonta à ideia de que as cores são, em última análise, intensidades distintas de escuridão. Uma das evidências mais fortes da presença dessa concepção é o fato de algumas crianças preverem que a utilização de canetinhas poderia gerar o branco. Para essas crianças, a canetinha era tida como sendo mais clara que o lápis e, portanto, deveria produzir o branco. Apesar da incoerência conceitual, visto que a canetinha também está inserida no conjunto da cor-pigmento, interpretamos que esse tipo de enunciação pode ser um princípio do processo de construção do conceito de absorção, conceito este pertinente para a explicação da situação proposta.

Outra verificação importante diz respeito à ideia de que a cor é uma propriedade dos objetos, não considerando a forma como o objeto é iluminado. Essa é uma afirmativa recorrente em algumas crianças pesquisadas e ressalta a lógica dos atributos, algo muito comum nessa faixa etária.

A nossa pesquisa acrescenta a essa discussão por tentar explicar o mecanismo psicológico utilizado pelas crianças para abordar, propor soluções e reorientar explicações e previsões a partir dos resultados de sua ação. Nesse sentido, identificar invariantes operatórios utilizados é uma atividade que se revela importante ao possibilitar a construção de um quadro não somente descritivo, mas também e sobretudo explicativo para a conceitualização enquanto o processo está ocorrendo.

Esse poder explicativo se coloca em um sentido mais restrito, quando se trata de investigar uma única faixa etária, posto que não se estabelece uma linha genética para a construção e evolução desses invariantes ao longo de larga escala de tempo. Esses resultados, mesmo que ainda restritos a determinada faixa etária, já possuem implicações em salas de aula, no processo de planejamento das intervenções didáticas nesse tema.

Mas, ao se colocar como uma peça ao longo de pesquisas realizadas com diferentes públicos de diversas faixas etárias, permite uma explicação mais completa sobre os principais caminhos que o processo de conceitualização pode seguir.

Nesse sentido, já nos foi possível perceber uma rota importante ligada ao conceito de absorção entre crianças de 4 - 5 anos e as da atual pesquisa, qual seja a ideia de que os diferentes pigmentos "tampam” parte da luz e que as suas misturas conduzem a uma cor muito escura.

Esperamos que o desenvolvimento das outras pesquisas com adolescentes e adultos, usando espaços escolares e não-escolares, nos permita construir um quadro mais amplo que explique a evolução dos invariantes operatórios utilizados e como eles contribuem para o processo de conceitualização. 
A pesquisa ora relatada pode, também, ser uma das bases para investidas de outros pesquisadores na área de educação em ciências que necessitem de um suporte da TCC em suas investigações posto que apresenta linhas gerais desta teoria e sua apropriação para o campo.

\section{REFERÊNCIAS}

BARDIN, L. L'analyse de contenu. Paris: PUF, 1977.

CARVALHO, A.M.P.; VANNUCCHI, A. I.; BARROS, M. A. Ciências no Ensino Fundamental : o conhecimento físico. São Paulo : Scipione, 2007.

CARVALHO JR., G. D. Invariantes Operatórios na transição entre dois campos conceituais : o caso do tempo relativo. UFMG. Faculdade de Educação. Tese (Doutorado em Educação), 2013.

CARVALHO JR., G. D., PARRAT-DAYAN, S. Recortes históricos sobre a noção de schème em Piaget: o processo de desenvolvimento de um conceito. Revista Brasileira de Estudos Pedagógicos, Brasília, v. 96, n. 244, p. 522-540, set./dez, 2015.

CARVALHO JR, G. D., SOUZA, T. P. P. Invariants opératoires utilisés par les enfants sur la formation de couleurs. La Recherche en Education, n. 17 (2017), p. 7 - 26, 2017.

CASTRO, D, RODRIGUEZ, J. 8-9 year old pupils' mental representations of light: teaching perspectives. Journal of Advances in Natural Sciences, v. 2, n. 1, 2014.

GONÇALVES, M.E.R.; CARVALHO, A.M.P. As Atividades de Conhecimento Físico : um exemplo relativo à sombra. Caderno Brasileiro de Ensino de Física, Florianópolis, v.12, n.1, p.7-16, 1995.

INHELDER, B., SINCLAIR, H. ; BOVET, M. Apprentissage et Structures de la Connaissance. Paris : PUF, 1974.

PARRAMÓN, J. M. Le grand livre de la couleur. Paris : Bordas, 1993.

OTERO, M. R.; FANARO, M. A.; SUREDA, P.; LLANOS, V. C.; ARLEGO, M. La Teoría de los Campos Conceptuales y la Conceptualización en el aula de Matemática y Física. Buenos Aires : Dunken, 2014.

PIAGET, J.; GARCIA, R. Vers une logique de significations. Genève: Murionde, 1987.

PIAGET, J.; INHELDER, B. Le développement des quantités physiques chez l'enfant. Neuchâtel : Delachaux et Niestlé, 1968.

PIAGET, J. Biologia e conhecimento : ensaio sobre as relações entre as regulações orgânicas e os processo cognoscitivos. Petrópolis : Vozes, 2000.

PIAGET, J. La causalité physique chez l'enfant. Paris : Félix Alcan, 1927.

PIAGET, J. La construction du réel chez l'enfant. Neuchâtel : Delachaux et Niestlé, 1967.

PIAGET, J. Le développement de la notion de temps chez l'enfant. Paris : PUF, 1973. 
RAVANIS, K.; CHARALAMPOPOULOU, C.; BAGAKIS, G. La formation des ombres dans la pensé des enfants de 5-6 ans. SPIRALE - Revue de Recherches en Éducation, n 36, p. 87-98, 2005.

VERGNAUD, G. La théorie des champs conceptuels. Recherches en Didactique des Mathématiques, v. 10, n. 23 , p. $133-170,1990$.

VERGNAUD, G. Langage et pensée dans l'apprentissage des mathématiques. Revue française de pédagogie, vol. 96, p. 79-86, 1991.

VERGNAUD, G. A comprehensive theory of representation for Mathematics Education. Journal of Mathematical Behavior, v. 2, n. 17, p. 167-181, 1998.

VERGNAUD, G. L'explication est-elle autre chose que la conceptualisation? In: LEUTENEGGER, F., SAADA-ROBERT, M. (ed.). Expliquer et comprendre en sciences de l'éducation, Genève: De Boeck, pp. 31-44, 2002.

VERGNAUD, G. O que é aprender ? In : BITTAR, M. e MUNIZ, C. A. (org.). A Aprendizagem Matemática na perspectiva da Teoria dos Campos Conceituais. Curitiba: CRV, p.13-35, 2009.

\section{NOTAS}

1 Para mais exemplos sobre invariantes operatórios encontrados em outros domínios da pesquisa científica, sugerimos consultar :CAMPOS, A. A Conceitualização do Princípio de Conservação de Energia Mecânica : Os Processos de Apredizagem e a Teoria dos Campos Conceituais. Tese (Doutorado em Educação) - Faculdade de Educação, USP, São Paulo. 2014. CARVALHO JR., G. D. Invariantes Operatórios na transição entre dois campos conceituais: ocaso do tempo relativo. Tese (Doutorado em Educação) - Faculdade de Educação, UFMG, Belo Horizonte. 2013.

Submetido em 19/04/2019

Aprovado em 21/10/2019

\section{Contato:}

Rua Afonso Sardinha, 90 - Bairro Pioneiros

CEP 36.420-000 - Ouro Branco, MG - Brasil 